\title{
Sürdürülebilir kalkınma hedeflerine erişmede hemşirenin önemi
}

\author{
Meral MADENOĞLU KIVANÇa ${ }^{\mathrm{a}}$, Sevda TÜREN ${ }^{\mathrm{b}}$, Rahime ATAKOĞLU ${ }^{\mathrm{c}}$, Cennet KARA ÖZÇALIK ${ }^{\mathrm{d}}$
}

\section{ÖZET}

Bu çalışmada, sürdürülebilir kalkınma hedeflerine ulaşmak için hemşirenin rolünü ortaya koymak amaçlanmıștır. Sürdürülebilir kalkınma, son yüzyılın en çok kullanılan kavramlarından biridir. Geçtiğimiz 50 yıl içerisinde sürdürülebilir kalkınma giderek önem kazanmış ve çevre sorunları üzerine odaklanmıştır. Sürdürülebilir kalkınma hedefleri; dünyanın refahını, barışını güçlendirmeyi, yoksulluk ve açlı̆̆ın giderilmesini aynı zamanda çevreyi korumayı hedefleyen bir eylem planı olarak ortaya çıkmıştır. Bu eylem planı, 2015 yılında Birleşmiş Milletler tarafından dikkate alınmıştır. Birleşmiş Milletler 2030 yılına kadar ortaya konan eylem planındaki 17 hedef ile ilgili çalışmalar başlatmıştır. Bu amaçla uluslar, mevcut politika ve stratejilerinde değiş̧ikliklere gitmişlerdir. Örneğin; doğal kaynakları korumak, sağlıkta ihtiyaçları karşılamak vb. sürdürülebilir kalkınmanın hedeflerine erişmede ekip çalışması, iletişim, objektif performans değerlendirme gibi faktörler söz konusudur. Hemşireler, toplum ve çevre sağlığının gelişmesinde önemli role sahiptir. Uluslararası Hemşireler Birliği; sürdürülebilir kalkınma hedeflerine ulaşmada hemşirelerden birey, meslek üyesi ve multidisipliner ekibin üyesi olarak yapması gereken sorumlulukları yerine getirmesini beklemektedir. Böylece hemşireler sürdürülebilir kalkınma hedeflerine erişmede değişim ve gelişim ajanı olarak görülebilir.

Anahtar kelimeler: Hemşire, sürdürülebilirlik, sürdürülebilir kalkınma

\section{In achieving sustainable development goals importance of the nurse}

\begin{abstract}
In this study, it is aimed to reveal the role of the nurse in order to achieve sustainable development goals. Sustainable development consists of the most used concepts of the last century. In the past 50 years, sustainable development has gained importance and environmental issues have been focused on. Sustainable development has emerged as an action plan that aims to strengthen the world's welfare, peace and alleviate poverty and hunger, as well as protect the environment. This action plan was created by the United Nations in 2015. The United Nations have initiated studies on 17 targets in the action plan that have been planned to be completed by 2030. To this end, nations have made changes in their existing policies and strategies such as protecting natural resources, meeting health needs, etc. Factors such as teamwork, communication, and objective performance evaluation are involved in achieving the goals of sustainable development. Nurses play an important role in the development of community and environmental health. International Nurses Association have determined the responsibilities that nurses should take as individuals, professionals and members of the multidisciplinary team in achieving the goals in sustainable development. Thus, nurses could be seen as change and development agents in achieving sustainable development goals.
\end{abstract}

Keywords: Nurse, sustainability, sustainable development

Gelis Tarihi: 23.05.2020 Kabul Tarihi:12.10.2020

å̇stanbul Kültür Üniversitesi SağlıkBilimleri Fakültesi Hemşirelik Bölümü, İstanbul, Türkiye, e-posta:m.kivanc@iku.edu.tr ORCID: 0000-0001-57872764

bỉstanbul Kültür Üniversitesi Sağlık Bilimleri Fakültesi Hemșirelik Bölümü, İstanbul, Türkiye, e-posta: sevdamercanhm@hotmail.com ORCID 0000-0003$1123-5879$

ċ̇stanbul Kültür Üniversitesi Sağlık Bilimleri Fakültesi Hemşirelik Bölümü, İstanbul, Türkiye, e-posta: r.atakoglu @ iku.edu.tr ORCID: 0000-0002-5157-1810 dİstanbul Kültür Üniversitesi Sağlık Bilimleri Fakültesi Hemşirelik Bölümü, İstanbul, Türkiye, e-posta: cennetkara2018@ gmail.com ORCID: 0000-00032394-2634

Sorumlu Yazar/Correspondence: Meral Madenoğlu Kıvanç e-posta: m.kivanc@iku.edu.tr

*Bu çalışma 01-03 Kasım 2019 tarihinde Gaziantep’te düzenlenen 1.Uluslararası Hemşirelik Bakımı ve Araştırma Kongresinde poster olarak sunulmuştur.

Atıf: Madenoğlu Kıvanç M, Türen S, Atakoğlu R, Kara Özçalık C. Sürdürülebilir kalkınma hedeflerine erişmede hemşirenin önemi. Sağllk ve Yaşam Bilimleri Dergisi 2020;2(2):74-78.

Citation: Madenoglu Kivanc M, Turen S, Atakoglu R, Kara Ozcalik C. In achieving sustainable development goals importance of the nurse. Journal of Health and Life Science 2020;2(2):74-78. 


\section{GíRiş}

Sürdürülebilir kalkınma düşüncesinin temelini, doğanın olumsuz etkilenmesi oluşturmaktadır. Küresel ısınma, su kaynaklarının tükenmesi, artan nüfus, ozon tabakasının tahribatı ve yoksulluk bu olumsuz faktörlerden bazılarıdır. Sürdürülebilir kalkınma, dünyanın yetersiz kaynaklarını sadece bazıları için değil tüm insanlar için etkili ve verimli bir şekilde kullanarak adaleti ve ekonomik gelişmeyi sağlamaktır. ${ }^{1-3}$ Sürdürülebilir kalkınma için toplumları teşvik etmek ve herkese eşit olarak adaleti sağlamak önemlidir. Sürdürülebilirlik kalkınma süreci 1972'de "Stockholm Çevre Konferansı" ile başlayıp 2002 yılı "Dünya Sürdürülebilir Kalkınma Zirvesi" ile günümüze kadar devam etmiş ve halen devam etmektedir. Sürdürülebilir kalkınma sürecinin yıllara göre özet başlıkları aşağıdaki gibi sıralanmaktadır;

1972 Stockholm Çevre Konferansı

1974 Akdeniz Eylem Planı

1976 Habitat I Toplantıs1

1984 Japonya Toplantıs1

1987 Brundtland Raporu

1992 Rio Konferans1

1995 Kopenhag ve Habitat II Toplantısı

1997 Kyoto Toplantısı

2000 BM Bin Y1l Kalkınma Toplantısı

2002 Dünya Sürdürülebilir Kalkınma Toplantısı

Ülkeler, yerel yönetimleri ve kurumlarıyla 2030 yılına kadar sürdürülebilir kalkınma hedeflerine ulaşmayı planlamaktadır. $\mathrm{Bu}$ hedefler; yoksulluğu sona erdirmek, herkesin refahını sağlamak, herkese eşit derecede kaliteli eğitim yapmak, toplumsal cinsiyet eşitliğini sağlamak, temiz su vb. sağlıklı koşulları vermek, güvenilir, enerji sağlamak, ekonomik büyümeyi sağlamak, sanayi yenilikçilik ve alt yapıyı geliştirmek, ülkelerin içindeki ve aralarındaki eşitsizlikleri azaltmak, sürdürülebilir şehir ve yaşam alanları sağlamak, üretimi sağlamak, iklim değişikliği ve etkileri ile mücadele etmek, deniz kaynaklarını sürdürülebilir kılmak, ormanların sürdürülebilirliğini sağlamak, çölleşme ile mücadele etmek, barışçıl toplumları oluşturmak, herkesin adalete erişimini sağlamaktır. Sürdürülebilir kalkınma için göz önünde bulundurulması gerekenlerden bazıları; nüfus politikasının sağlanması, verimliliğin artırılmasının sağlanması, ekonomik büyümenin istikrarlı hale getirilmesi, gelir dağılımının adil olmasının sağlanmasıdır., ${ }^{4,8}$

Ülkelerin gelişmesi sürdürülebilir kalkınma hedeflerine ulaşmakla mümkündür. Küresel olayların başında sağlık sorunları gelmektedir. Sağlık, toplum için önemli olup artan hava kirliliği, daha fazla vektör kaynaklı hastalıklar, ormanların azalması, zararlı atıkların yayılmasından doğrudan etkilenmektedir. $\mathrm{Bu}$ olaylardan özellikle çocuklar, yaşlı yetişkinler, kronik hastalığı olan bireyler ve yoksullar zarar görmektedir. Hemşireler, küresel sorunların sağlık üzerindeki etkilerini azaltmak için faaliyetlerde bulunarak sürdürülebilir kalkınmada etkin rol oynayabilirler. ${ }^{4} \mathrm{Bu}$ makalede, ülkelerin sürdürülebilir kalkınmasında hemşirelerin önemli olduklarının açıklanması ve farkındalık yaratılması amaç edinilmiştir.

\section{Sürdürülebilir Kalkınma ve Boyutları}

Sürdürülebilir kalkınma, "Bugünün ihtiyaçlarını, gelecek kuşakların da kendi ihtiyaçlarını karşılayabilme olanağından ödün vermeden karşılamaktır" şeklinde tanımlanmaktadır. ${ }^{5}$ Sürdürülebilir kalkınma hedeflerine ulaşırken özelliklerini hatırlamak gerekir. Bu özellikler;

- Sürdürülebilir kalkınmanın en önemli unsuru bireylerdir.

- Sürdürülebilir kalkınma, bir süreci temsil etmektedir.

- Sürdürülebilir kalkınmanın amacı, kendini yenileyebilen bir yönetim kültürü sağlamasıdır.

- Sürdürülebilir kalkınma, planlı ve önemli bir kurumsal değişim ve dönüşüm sürecini ifade etmektedir.

- Sürdürülebilir kalkınma, gönüllülük esasına dayalı katılımcı yöntemlerinin kullanıldığı süreçtir.

- Sürdürülebilir kalkınma, yenilikçi bir süreci ifade etmekte bilimsel ve teknolojik gelişmelerin kullanımını desteklemektedir. ${ }^{1}$

Sürdürülebilir kalkınma; çevresel, ekonomik ve sosyal sürdürülebilirliği kapsamakta olup bu da fiziksel, doğal ve insan kaynaklarının en iyi şekilde yönetilmesiyle gerçekleştirilebilir. Sürdürülebilir kalkınmanın başarılı olabilmesi için kavramın çevresel, ekonomik ve sosyal boyutu üzerinde durulmakta ve eş zamanlı olarak işbirliğinin sağlanması gerekmektedir. ${ }^{6-10} \mathrm{Bu}$ boyutlar sürdürülebilir kalkınmanın vazgeçilmez unsurlarıdır. ${ }^{1}$

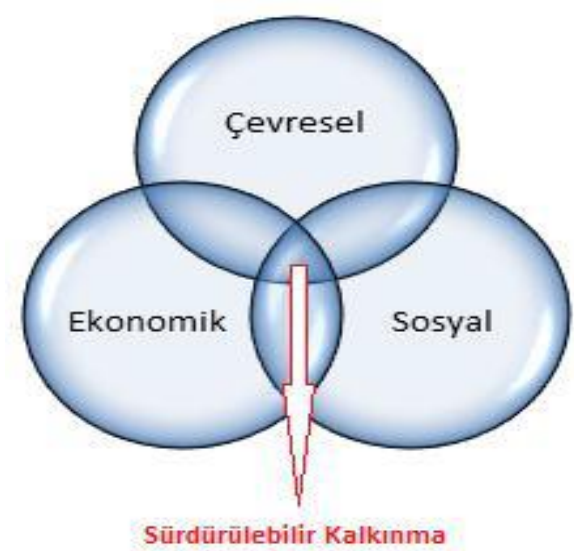

Sürdürülebilir kalkınmanın boyutları 
Çevresel kalkınma: Doğaya ve tüm yaşayan canlıların sağlığına verilen zararın en aza indirgenmesi, sanayileşmenin çevre üzerindeki olumsuz etkilerinin ortadan kaldırılarak doğal kaynakların sürekliliğinin sağlanmasıdır. Teknolojik gelişmeler olumlu değişmeler yaratmakla birlikte çevreyi kirletmekte sağlık alanında riskli ortam yaratmaktadır. Çevre kirliliğinin, sağlığın bozulmasındaki etkileri kaçınılmazdır. Bunun için alınması gereken önlemler arasında; etkin çevre politikaları, yasal düzenlemeler, etkin kaynak kullanımı, çevreyi koruyan ve geliştiren yöntemlerin uygulanması sayılabilir. Alınacak bu önlemler çevresel kalkınmaya katkıda bulunabilir².

Ekonomik kalkınma: Ekonomik refahta kazanımlar elde edilmesi için fakirliğin azaltılması ya da yok edilmesi önemlidir. Adaletin özendirilmesi ve insanların fakirleştirilmemesi için eşit olmayan paylaşımdan kaçınılması, yatırım politikalarının sağlanması ekonomik kalkınmada rol oynayabilir. Kalkınmışlık toplumun sağlık düzeyinin yükselmesine yol açabilir. ${ }^{3}$

Sosyal kalkınma: Sosyal eşitliği açıklar. Sağlık ve eğitimi içine alan sosyal hizmetlerin yeterli düzeyde karşılanması gerekmektedir. Kaynakların eşit dağılımı, cinsiyet eşitliği sosyal kalkınma boyutunda da önemli olmaktadır. $^{1}$

Toplumun tüm kesimlerine uygulanacak politikalara aktif olarak katılma, ekonomik, sosyal ve çevre boyutu arasında eşgüdümü sağlama sürdürülebilir kalkınmayı bir zorunluluk değil yaşam tarzı haline getirmektedir. ${ }^{5}$

Sürdürülebilir kalkınmada gelişme önemlidir ve genel olarak insan refahında sağlanan artış biçiminde tanımlanmaktadır. Sürdürülebilir gelişmenin amaçları arasında; iş bölümü, katılımcı yönetim anlayışı, güven ortamının yaratılması ve değişime olumlu bir yaklaşım söz konusudur. Uluslar; sürdürülebilir gelişmeye olanak verecek stratejilerini geliştirmek durumundadırlar. Bu amaçla istikrarlı bir şekilde nüfus düzeyinin sağlanması, sağlık konularında temel gereksinimlerin karşılanması ve doğal kaynakların korunması gibi mevcut politika ve stratejilerinde değişiklikler yaratmaları gerekmektedir. ${ }^{11}$ Sürdürülebilir gelişmenin unsurları arasında;

Eşitlik ve Adalet: Rio Bildirgesi'nde "gelişme hakkının şimdiki ve gelecek kuşakların çevre ve gelişme gereksinimlerini eşitlik ve adalete dayalı olarak sağlayabilecek bir biçimde kullanılması" gereği üzerinde durulmuştur. İstanbul Bildirgesi'nde "adalet" kavramı, sürdürülebilir gelişmenin önemli faktörlerinden olarak kabul edilmiştir. ${ }^{1}$

Uzmanlaşma: Sürdürülebilir gelişme ekonomik, toplumsal ve çevresel gelişmelerin birbiriyle gelişme düşüncesini dengede tutulması sürecidir. Sürdürülebilir gelişme stratejilerinin yürütülmesi çalışanlar arasında uzmanlaşmayı gerektirmektedir. ${ }^{5}$

Yardımlaşma: Rio Bildirgesi sürdürülebilir gelişmenin amaçlarının gerçekleştirilmesi için işbirliği yapılması gerektiğini kabul etmektedir. Sürdürülebilirliğin hayata geçirilmesinde bu işbirliğinin ulusal ve uluslararası boyutta olması Habitat II Konferansı'nda önerilmiştir. ${ }^{5}$

Hizmette Yerellik: Halkın doğrudan katılımı ve yönetimi denetleyebilmesi için gerekli mekanizmaların oluşturulmasını ön görmektedir. ${ }^{6}$

Çok Ortaklı Yönetim: Sürdürülebilir gelişme düşüncesinin temeli "küresel düşün yerel hareket et" dir. Burada "yerel hareket" vatandaşların yönetim süreçlerine daha fazla katılımı ve yerel demokratik hareketin ifade etmektedir. Hükümet ve kuruluşların yerine getirdikleri faaliyetler sürdürülebilir gelişme için önemli olmaktadır. 5

Yeni Gelişme Düşüncesi: Sürdürülebilir gelişme statik bir süreç değil dinamik bir süreçtir. Aynı zamanda değişim ve gelişim süreci olarak görülmektedir. Bu süreçte yeni düşünceler söz konusudur. ${ }^{8}$

\section{Sürdürülebilir Kalkınmada Yönetim}

Kurumların, sürdürülebilir kalkınma stratejilerini belirlemeleri önemlidir. Bunu hayata geçirirken kurumlar sadece kendi içsel faktörlerini değil onları etkileyen tüm dışsal faktörleri gözardı etmeksizin organizasyon yapısı, kurum kültürü ve yönetim tarzlarını da baz alarak adım atmaları gerekmektedir. $^{12-14} \quad$ Kurumlar kaynakların kullanımında adil ve hesap verebilir olmayı ilke edindiğinde gelişmesini sürdürecektir. Kurumların başarı grafiklerinin yükselebilmesi için sürekli gelişmeleri ve sürdürmeleri gerekmektedir. Kurumlarda sürdürülebilirlik, gelecek nesillerin çıkarlarını gözeten bir anlayışın kurumların yönetimde hakim olmasıyla gerçekleşebilir. Bir kurumun sürdürülebilirlik ile ilgili sorumluluklarını yerine getirebilmesi için; sürdürülebilirlik hedeflerini oluşturması, sürdürülebilirlik anlayışını özümsemiş olması, sürdürülebilirlik faaliyetlerinin organizasyonun her kademesinde uygulanabilmesi için gerekli kültür ve sistemlerin oluşturulması gereklidir. ${ }^{14}$

Kurumların sürdürülebilirliğinin sağlanmasındaki en önemli etkenlerden biri sürekli öğrenme ortamının oluşturulmasıdır. Kurumların önemli bir parçası olan devamlı öğrenim, kurum kültürünün bir parçası haline getirilmelidir. Diğer önemli bir konu sürdürülebilirliğin raporlandırılmasıdır. ${ }^{15}$

Sürdürülebilirlik yönetimin kendi içinde çeşitli kısımlara ayrılan beş ayrı basamağı bulunmaktadır. ${ }^{16}$ $\mathrm{Bu}$ basamaklar; ilkelerin belirlenmesi ve planlama, 
uygulama, iletişim, gözden geçirme ve düzeltmedir. Sürdürülebilir kalkınma yönetiminde insan kaynakları ve insan ihtiyaçlarını karşılamaya odaklanma önemlidir. ${ }^{17}$

\section{Sürdürülebilir Kalkınmanın Hedeflerine Erișmede Hemşirenin Önemi}

Hemşireliğin öncelikli hedefi bireyin sağlığını korumak, geliştirmek, sağlığı bozulduğunda iyileşmesini hızlandırmaktır. Tarih boyunca hemşirelik girişimleri çevresel, ekonomik ve sosyal çevre içinde insan sağlığının iyileştirilmesi gibi sürdürülebilirlik çabalarını içermektedir. ${ }^{18}$

Toplumda değişim için hemşireler önemli çözümler geliştirebilirler ve bunun için planlama ve organizasyon yapabilirler. Hemşireler atıkların yönetimi konusundaki yaklaşımı ile çevresel sürdürülebilirliği etkileyebilir. Burada yaklaşımlar; tek kullanımlık malzemelerin kullanımı, ilaç ve kullanılan malzeme atıklarının dönüşümü, çevre dostu malzemelerin kullanımının tercihi, enerji yönetimi vb. bakımın sürdürülmesinde hemşirelerin değişime isteklilik duyması, sorumluluk sahibi davranışlarda bulunması ve geleceğe inanması önemlidir. Sürdürülebilir kalkınma için Uluslararası Hemşireler Birliği, hedeflere ulaşma ve gelişme için 2014-2018 yılları arasında sağlığın politikalarını etkilemek, sorunların çözümünde kanıta dayalı uygulamaları ortaya koymak, hizmet sunumunda adaleti sağlamak, stratejik liderlik gibi hedefler belirlemiştir. ${ }^{19}$

Uluslararası Hemşireler Birliği; hemşirelerin yapması gerekenleri ortaya koymuştur. Bunlar; sağlık kaynaklarına adil ulaşım, liderlik, ulusal dernekler ve diğer kuruluşlarla iş birliği yapmak ulusal hemşirelik derneklerinde ve meslek çalışanlarını bir araya getirmek. Hedeflere ulaşma konusunda dayanışma içinde olma, Ekip çalışması sağlamak, meslekler arası iletişim kurmaktır. ${ }^{20}$

\section{SONUC}

Ülkelerin sürdürülebilir kalkınmada izledikleri sağlıkla ilgili stratejilerde sağlıklı yaşamın sağlanması, ölüm oranlarının azaltılması, çocuk yaşta ortaya çıkan beslenme bozukluklarının önlenmesi gibi hemşirelik ile ilişkili hedefleri söz konusudur. Sağlık hizmetlerinin ilk basamağından olmak üzere toplum sağlığının kalitesini arttırmada hemşireler önemli role sahiptir. Hemşireler sürdürülebilir kalkınma için faaliyetlerini ortaya koymalıdırlar. Hemşirelere düşen, iyi bir vizyon ile mesleki örgütler arasında aynı zamanda çevre ve toplumla olumlu işbirliği sağlamalarıdır. İnsan sağlığı sorunlarının çözümü için hemşireler eğitim olarak da hazırlanmalıdır. $\mathrm{Bu}$ hazırlık hemşire liderlerini, eğitimcilerini ve uygulayıcılarını kapsayabilir. Hemşire eğitimciler iklim, çevre kirliliği vb. gibi küresel sorunların getireceği sorunlara ve bunun sağlık üzerindeki etkilere odaklanabilir ve müfredatlarını geliştirebilirler.

\section{KAYNAKLAR}

1. Çelik Y. Sürdürülebilir kalkınma ve sağlık. Hacettepe Sağllk İdaresi Dergisi. 2006;9(1):20.

2. Karabıçak M, Özdemir BM. Sürdürülebilir kalkınmanın kavramsal temelleri. Süleyman Demirel Üniversitesi Vizyoner Dergisi. 2015;6(13):44-49.

3. Yeni O. Sürdürülebilirlik ve sürdürülebilir kalkınma. Bir yazın taraması. Gazi Üniversitesi İktisadi ve İdari Bilimler Fakültesi Dergisi. 2014;16(3):181-208.

4. Anaker A, Elf M. Sustainability in nursing: a concept analysis. Scand J Caring Sci. 2014;28:381389.

5. Lale Z. Sürdürülebilir kalkınma temeline yaşanabilir çevre oluşturması: Eskişehir Tepebaşı ilçesi örneği. Anadolu Üniversitesi Sosyal Bilimler Enstitüsü. Yüksek Lisans Tezi, Eskişehir, 2016.

6. Kaypak Ş. Küreselleșme sürecinde sürdürülebilir kalkınma için sürdürülebilir çevre. KMÜ Sosyal ve Ekonomik Araştırmalar Dergisi. 2011;13(20);1933.

7. Yangil FM. Kurumsal sürdürülebilirlik kapsamında sürdürülebilir raporlarına yönelik içerik analizi: Türkiye'deki en büyük 100 sanayi işletmesi. Işletme Araştırmaları Dergisi. 2015;7(3):356-376.

8. Tıraş H. Sürdürülebilir kalkınma ve çevre: Teorik bir inceleme. Kahramanmaraş Sütçü Imam Üniversitesi İktisadi ve İdari Bilimler Dergisi. 2012; 2(2):57-73.

9. Kesen M. İșletme Yönetiminde sürdürülebilir insan kaynaklar yönetiminin yeri ve önemi. Insan ve Toplum Bilimleri Araştırmaları. 2012;11(3):601626.

10. Akgül U. Sürdürülebilir kalkınma: Uygulamalı antropolojinin eylem alan1. Ankara Üniversitesi Dil ve Tarih Coğrafya Fakültesi Antropoloji Dergisi. 2010;24:133-164.

11. Çetin M. Bölgesel kalkınmaya farklı bir bakış: Çevre/yenilikçi çevre yaklaşımı. Erciyes Üniversitesi İktisadi ve Idari Bilimler Dergisi. 2004;18(3-4):35-49.

12. Aksu C. Sürdürülebilir kalkınma ve çevre. Güney Ege kalkınma Ajansı. 2011.

13. Evren M. Sürdürülebilirlik, sürdürülebilir kalkınma ve ülkemizdeki mevcut durum. Verimlilik Dergisi. 2018;28(335);10-15.

14. Argüden Y. Sürdürülebilir bir gelecek için yönetim kurullarının sorumlulukları. Yönetişim Dergisi. 2016;42-47.

15. Kuşat N. Sürdürülebilir işletmeler için kurumsal sürdürülebilirlik ve içsel unsurları. Afyon Kocatepe IIBFF Dergisi. 2012;14 (2):227-242.

16. Bıçakçı BA. Sürdürülebilirlik yönetiminde halkla ilişkilerin rolü. Sosyal ve Beşeri Bilimler Dergisi. 2012;4(1):47-56.

17. Doğru G. Kurumsal sürdürülebilirlikte stratejik insan kaynakları yönetiminin rolü. Dokuz Eylül Üniversitesi, Sosyal Bilimler Enstitüsü, Yüksek Lisans Tezi, İzmir, 2012. 
18. Altuğ Özsoy Ç, Gürgen Ş. Hemşirelik uygulamalarına yön veren uluslararası hemşirelik kuruluşlarının çevre sağlığı yaklaşımları. Anadolu Hemşirelik ve Sağllk Bilimleri Dergisi, 2018;21(1):51-59.

19. Oskay Ü, Büyükyılmaz F, Baydın NÜ, KaramanA, Yılmaz B, Akyüz F. 2017 Uluslararası hemşireler birliği temasına genel bakış. Florence Nightingale Hemșirelik Dergisi. 2018;26(1):69-78.

20. ICN, http://www.icn.ch/, Erişim:10.09.2019. 